\title{
Preparation and Optical Properties of CdS-Microcrystallites Deposited in Porous Vycor Glass
}

\author{
Ichiro TANAHASHI, Yoshio MANABE and Tsuneo MITSUYYU \\ Central Research Laboratories, Matsushita Electric Industrial Co., Ltd., 3-1-1, Yagumo-Nakamachi, Moriguchi-shi, Osaka \\ 多孔質バイコールガラス担持 CdS 微粒子の調製と光学特性 \\ 棚橋一郎・真鍋由雄・ 三露常男 \\ 松下電器産業(株) 中央研究所, 570 大阪府守口市八雲中町 3-1-1
}

570

[Received March 4, 1993; Accepted May 21, 1993]

\begin{abstract}
CdS-microcrystallites were prepared in porous Vycor glass (PVG) by impregnation of PVG with an aqueous solution of $\mathrm{Cd}\left(\mathrm{NO}_{3}\right)_{2} \cdot 4 \mathrm{H}_{2} \mathrm{O}$ and subsequent reaction with $\mathrm{H}_{2} \mathrm{~S}$ gas. The optical absorption edge of the $\mathrm{CdS}$ / PVG containing $1.0 \mathrm{wt} \%$ cadmium exhibited a blue shift by $0.37 \mathrm{eV}$ compared to bulk CdS, indicating the quantum size effect. The blue shift decreased with increasing diameter of CdS-microcrystallites in PVG. In the photoluminescence spectra of the $\mathrm{CdS} / \mathrm{PVG}$, the band-edge emission and the deep-level emission were observed. In accordance with the optical absorption spectra, the blue-shifted band-edge emission was also observed. The deep-level emission was effectively quenched by heating the $\mathrm{CdS} / \mathrm{PVG}$ up to $300^{\circ} \mathrm{C}$ in air or by addition of methyl viologen $\left(\mathrm{MV}^{2+}\right)$ as an electron acceptor, suggesting that the emission arose from electron-hole pair recombination on the surface of CdSmicrocrystallites.
\end{abstract}

Key-words : CdS-microcrystallites, Porous Vycor glass, Optical nonlinearity, Optical absorption, Photoluminescence

\section{Introduction}

Recently, semiconductor/glass composites with large third-order optical nonlinearity have attracted much interest as materials for optical functional devices, such as optical switches, shutters or waveguides.1)-4) The large nonlinearity of the composites is interpreted by the quantum size effect. In fact the diameter of semiconductor microcrystallites in the glass matrices was under $10 \mathrm{~nm}$. Thus the microcrystallites are considered as "quantum dots."

CdS-microcrystallites/glass composites have been prepared by various methods such as melt-quenching,5)-7) sol-gel, 8)-10) sputtering deposition, 11)-13) and precipitation in porous matrices. ${ }^{14)-16)}$ Optical properties of CdS-microcrystallites are known to be different by the preparation methods.

Kuczynski and Thomas have investigated the photophysical properties of $\mathrm{CdS}$ deposited in porous Vycor glass (PVG). ${ }^{14)}$ It is known that PVG has the porous channels and the CdS in PVG must have one dimension much smaller than $4 \mathrm{~nm}$, i.e., the diameter of the cylinders in the PVG. However, they reported that the spectroscopic properties of $\mathrm{CdS}$ in PVG were indicative of bulk CdS material. Therefore, information on the optical properties of CdSmicrocrystallites deposited in PVG is not sufficient.

In the present work, by means of optical absorption and emission spectra measurements, we have investigated the optical properties of CdS-microcrystallites deposited in PVG.

\section{Experimental}

Porous Vycor glass (PVG) used was a product of Corning (No. 7930), the size being about 10 $\mathrm{mm} \times 10 \mathrm{~mm}$ in length and $1.0 \mathrm{~mm}$ in thickness with the specific surface area of $232 \mathrm{~m}^{2} \cdot \mathrm{g}^{-1}$ and the average pore size of $4.4 \mathrm{~nm}$. From the $\mathrm{N}_{2}$ adsorption isotherm, the surface area and the pore size of the PVG were obtained by using the well-known BETequation and by the " $t$-method", respectively. ${ }^{17)}$

The following gas and chemicals were used without further purification: a gas mixture of $19.6 \%$ $\mathrm{H}_{2} \mathrm{~S}$ and $80.4 \% \quad \mathrm{~N}_{2}$ (Nippon Sanso K.K.), and Methyl viologen, 1.1'-dimethyl-4.4' bipyridinium dichloride (Sigma Chemical Co.), and $\mathrm{Cd}\left(\mathrm{NO}_{3}\right)_{2}$. $4 \mathrm{H}_{2} \mathrm{O}$ (Kojundo Chemical Laboratory Co., Ltd., 99.99\%).

Figure 1 shows the schematic preparation process of CdS/PVG. First, PVG was cleaned in $30 \% \mathrm{H}_{2} \mathrm{O}_{2}$ solution for over $24 \mathrm{~h}$, then heated at $180^{\circ} \mathrm{C}$ in air. $\mathrm{CdS} / \mathrm{PVG}$ was prepared by soaking the cleaned PVG in an aqueous solution of $0.1-1.0 \mathrm{~mol} \cdot \mathrm{dm}^{-3} \mathrm{Cd}$ $\left(\mathrm{NO}_{3}\right)_{2} \cdot 4 \mathrm{H}_{2} \mathrm{O}$ for $70-90 \mathrm{~h}$ at room temperature and

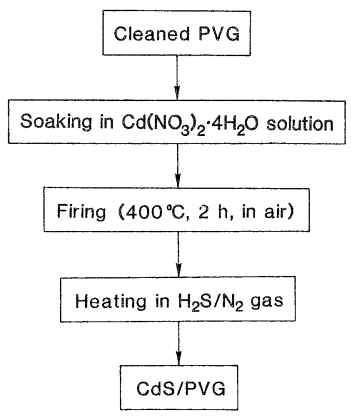

Fig. 1. Schematic preparation process of CdS/PVG. 
firing the $\mathrm{PVG}$ at $400^{\circ} \mathrm{C}$ for $2 \mathrm{~h}$ in air, thereby leaving the cadmium oxide in PVG. Precipitation of CdS in PVG was carried out by heating the PVG with cadmium oxide in the glass tube with flowing the dried gas mixture of $19.6 \% \mathrm{H}_{2} \mathrm{~S}$ and $80.4 \% \mathrm{~N}_{2}$ in the temperature range between 50 and $300^{\circ} \mathrm{C}$. The cadmium content was $0.2-2.1 \mathrm{wt} \%$ determined by ICP emission spectroscopy. The subsequent heat treatment of $\mathrm{CdS} / \mathrm{PVG}$ was carried out at $100-300^{\circ} \mathrm{C}$ in air to investigate the origin of photoluminescence of the deposited CdS in PVG. The obtained CdS/PVG samples were yellow or orange in color and are quite transparent for use in optical studies.

$\mathrm{X}$-ray photoelectron spectra (XPS) analyses were performed using a $\mathrm{Mg} \mathrm{K} \alpha \mathrm{X}$-ray source. Typical operating conditions were as follows: X-ray gun, 13 $\mathrm{kV}, 10 \mathrm{~mA}$; the pressure in the analytical chamber, less than $4.8 \times 10^{-7} \mathrm{~Pa}$. The measurement of the electron spectra was carried out after in situ scraping of the films surface with a diamond file until no further change in the photoemission spectra was observed. For the calculation of binding energies of each peak, the peak position of the main component in the $1 \mathrm{~s}$ core level spectrum of carbon was assumed to be $284.6 \mathrm{eV}$. X-ray diffraction (XRD) measurements were carried out to examine the crystallinity of CdSmicrocrystallites in PVG. The optical absorption spectra were measured in the range from 300 to 800 $\mathrm{nm}$ by a spectrometer at room temperature. The photoluminescence (PL) measurements were carried out in the temperature range between -261 and $27^{\circ} \mathrm{C}$ by using a spectroflurophotometer with filters to eliminate the excitation light. The excitation wavelength was $325 \mathrm{~nm}$. The typical excitation power density was as low as $0.04 \mathrm{~W} \cdot \mathrm{cm}^{-2}$. The lifetime measurements for the PL were performed using a $\mathrm{N}_{2}$ laser with $0.8 \mathrm{~ns}$ pulse width at room temperature.

\section{Results and discussion}

The states of the chemical bond of CdS/PVG have been evaluated by XPS. The Si $2 p$ and O1s electron spectra of the CdS/PVG containing $1.0 \mathrm{wt} \%$ of cadmium are shown in Figs. 2 and 3. The reaction temperature with $\mathrm{H}_{2} \mathrm{~S}$ was $150^{\circ} \mathrm{C}$ for $10 \mathrm{~min}$. In the figures, the arrow indicates the standard peak position of $\mathrm{Si} 2 \mathrm{p}$ and $\mathrm{O} 1 \mathrm{~s}$ of $\mathrm{SiO}_{2}{ }^{18)}$ The observed peak position of the CdS/PVG is very close to that of $\mathrm{SiO}_{2}$. Thus the main component of the PVG was $\mathrm{SiO}_{2}$. The XRD patterns of the CdS/PVG containing $2.1 \mathrm{wt} \%$ of cadmium showed the typical amorphous $\mathrm{SiO}_{2}$ halo pattern. Because of low CdS concentration in the PVG, the diffraction pattern of CdS could not be observed.

Figure 4 shows the $\mathrm{Cd} 3 \mathrm{~d}$ electron spectrum of the $\mathrm{CdS} / \mathrm{PVG}$. The examined CdS/PVG was the same as shown in Figs. 2 and 3. In the figure, the arrows indicate the standard peak position for CdS, Cd metal, and $\mathrm{CdO} .{ }^{19)}$ The experimental peak position is close to the standard CdS. In conclusion, the CdS was successfully deposited in porous $\mathrm{SiO}_{2}$ glass.

Figure 5 shows the absorption spectra measured at room temperature for the CdS/PVG containing $1.0 \mathrm{wt} \%$ of cadmium. In the case of CdS/PVG (a), the reaction temperature with $\mathrm{H}_{2} \mathrm{~S}$ was $50^{\circ} \mathrm{C}$ for 10 min, (b) $150^{\circ} \mathrm{C}$ for $10 \mathrm{~min}$, and (c) $300^{\circ} \mathrm{C}$ for $10 \mathrm{~min}$. The color of the CdS/PVG changes from bright yellow to orange with increasing the reaction temperature with $\mathrm{H}_{2} \mathrm{~S}$. In the figure, the band-edge of $\mathrm{CdS} /$ PVG shifts to longer wavelength with increasing the reaction temperature. This is because the diameter of the microcrystallites became large. An absorption peak or a shoulder corresponding to the transition from the highest valence subband to the lowest conduction subband cannot be observed. This is due to the wide distribution of size in CdS-microcrystallites.

From the spectra, the power of the absorption coefficient $\alpha$ was plotted against the photon energy $h v$. The $\alpha^{2}$ varied linearly with $h v$ indicating that the direct inter-band transition takes place. The band gap energy, $E_{\mathrm{g}}$, of the CdS/PVG (a) is clearly blueshifted by about $0.37 \mathrm{eV}$ compared with that of the

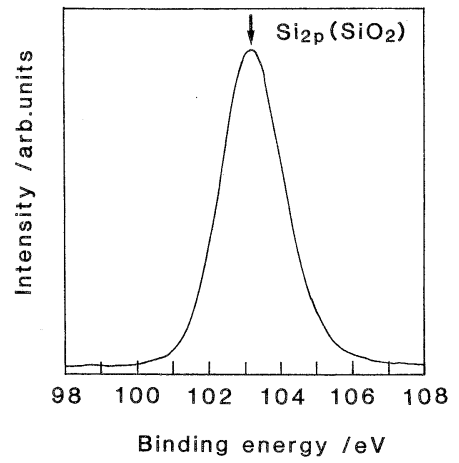

Fig. 2

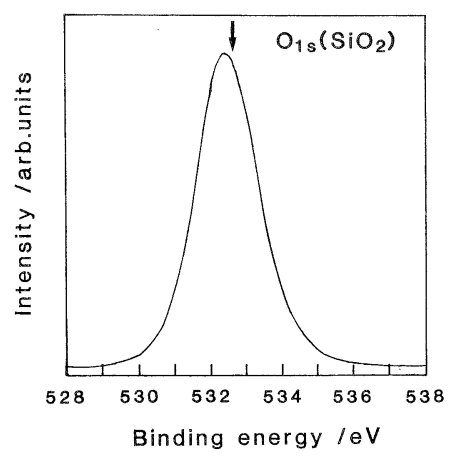

Fig. 3

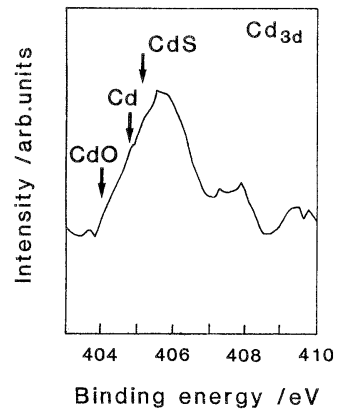

Fig. 4

Fig. 2. Si $2 \mathrm{p}$ electron spectrum of the $\mathrm{CdS} / \mathrm{PVG}$ containing $1.0 \mathrm{wt} \%$ of cadmium.

Fig. 3. O1s electron spectrum of the CdS/PVG containing $1.0 \mathrm{wt} \%$ of cadmium.

Fig. 4. Cd 3d electron spectrum of the CdS/PVG containing $1.0 \mathrm{wt} \%$ of cadmium. CdS indicates the peak position of Cd $3 \mathrm{~d}$ electron spectra of CdS, Cd; Cd 3d of Cd metal, CdO; Cd 3d of CdO. 


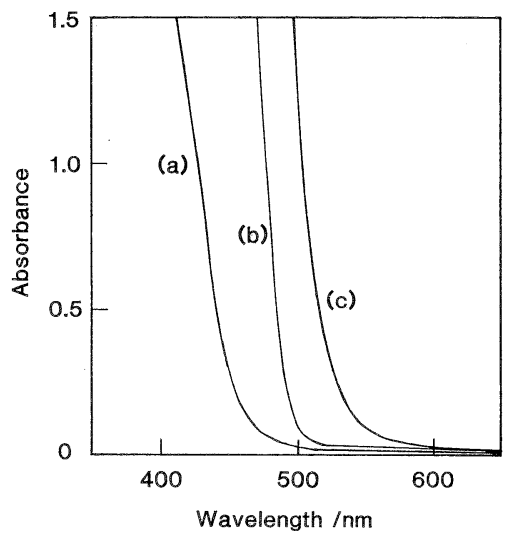

Fig. 5. Optical absorption spectra of the CdS/PVG containing $1.0 \mathrm{wt} \%$ of cadmium at room temperature, and the CdS/PVG (a) reacted with $\mathrm{H}_{2} \mathrm{~S}$ at $50^{\circ} \mathrm{C}$, (b) at $150^{\circ} \mathrm{C}$, and (c) at $300^{\circ} \mathrm{C}$.

bulk CdS (2.41 eV), (b) $0.2 \mathrm{eV}$, and (c) $0.11 \mathrm{eV}$. In spherical semiconductor microcrystallites enclosed by an insulating matrix, the blue shift, $\Delta E_{\mathrm{g}}$, is expressed by the following Eq. (1),

$$
\Delta E_{\mathrm{g}}=h^{2} / 8 a^{2} \mu
$$

where $a$ and $\mu$ are the radius of the spherical dots and the reduced effective mass of an electron-hole pair, respectively, and $h$ is Planck's constant. This equation is valid when the radius $a$ is smaller than the Bohr radius of the bulk exciton. ${ }^{20)}$ The diameter of CdS-microcrystallites in the CdS/PVG (a) was about $4.7 \mathrm{~nm}$, (b) $6.4 \mathrm{~nm}$, and (c) $8.6 \mathrm{~nm}$ calculated by Eq. (1). It is known that PVG is honeycombed with cylinders which showed a diameter of not more than about $4 \mathrm{~nm}$. Therefore, the CdS deposited in PVG cannot have one of its dimensions greater than $4 \mathrm{~nm}$. However, the diameter of CdS-microcrystallites in the CdS/PVG (a), (b), and (c) by the calculation was greater than $4 \mathrm{~nm}$. It seems that the $\mathrm{CdS}$ in the PVG is an elongated structure. The dimension of the CdS-microcrystallites along cylinders became larger with increasing the reaction temperature with $\mathrm{H}_{2} \mathrm{~S}$. Because of low CdS concentration in the PVG, the CdS-microcrystallites could not be observed directly by the transmission electron microscope (TEM) observation.

Figure 6 shows photoluminescence (PL) spectra measured at room temperature for various $\mathrm{CdS} /$ PVG. In the figure, the CdS/PVG (a), (b), and (c) were the same as those in Fig. 5. The cadmium concentration of the CdS/PVG (d) and (e) were 0.2 and $2.1 \mathrm{wt} \%$, respectively. For the CdS/PVG (b), (d), and (e), the reaction temperature with $\mathrm{H}_{2} \mathrm{~S}$ was $150^{\circ} \mathrm{C}$ for $10 \mathrm{~min}$. The emission spectrum for the CdS/PVG (a) consists of a peak at $467 \mathrm{~nm}$ and a weak shoulder at $514 \mathrm{~nm}$. The CdS/PVG (d) shows the emission with a peak at $482 \mathrm{~nm}$. In the case of low CdS concentration or low reaction temperature with $\mathrm{H}_{2} \mathrm{~S}$, deep-level emission was not observed, suggesting that defects were well suppressed. In accordance with the optical absorption spectrum, the energy of the band-edge emission of CdS/PVG (a) is

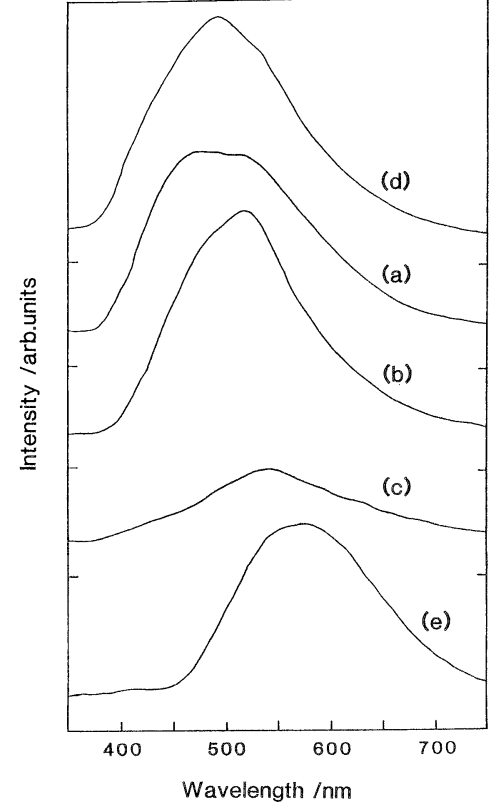

Fig. 6. Photoluminescence spectra at room temperature for (a) the $\mathrm{CdS} / \mathrm{PVG}$ containing $1.0 \mathrm{wt} \%$ of cadmium reacted with $\mathrm{H}_{2} \mathrm{~S}$ at $50^{\circ} \mathrm{C}$, (b) at $150^{\circ} \mathrm{C}$, (c) at $300^{\circ} \mathrm{C}$, (d) the CdS/PVG containing $0.2 \mathrm{wt} \%$ of cadmium reacted with $\mathrm{H}_{2} \mathrm{~S}$ at $150^{\circ} \mathrm{C}$, and (e) containing 2.1 wt $\%$ of cadmium reacted with $\mathrm{H}_{2} \mathrm{~S}$ at $150^{\circ} \mathrm{C}$.

about $0.25 \mathrm{eV}$ higher than that of the bulk CdS. The shift to higher energy is attributed to a low-dimensional quantum size effect due to confinement of electrons and holes in CdS-microcrystallites. The observed broad emission reflects contributions of wide distribution of CdS-microcrystallites size. The emission is probably due to the recombination of free electron-hole pair or the shallow donor-acceptor pair in the CdS-microcrystallites. ${ }^{21)}$ The peak position of emission spectra for the CdS/PVG (d) is $482 \mathrm{~nm}$, (b) $514 \mathrm{~nm}$, and (e) $574 \mathrm{~nm}$. It is clear that the peak shifts to lower energy with increase the concentration of CdS in PVG, suggesting that the long dimension of CdS-microcrystallites along the cylinder became large. The effect of reaction temperature with $\mathrm{H}_{2} \mathrm{~S}$ on emission spectra has also shown in Fig. 6 . In the figure, the peak position of the CdS/PVG (a) is $467 \mathrm{~nm}$, (b) $514 \mathrm{~nm}$, and (c) $539 \mathrm{~nm}$. The peak position also shifts to lower energy with increasing the reaction temperature. Therefore, the diameter of the CdS-microcrystallites was controlled by changing the reaction temperature with $\mathrm{H}_{2} \mathrm{~S}$.

In conclusion, the PL spectra of CdS/PVG were largely influenced by the diameter of CdSmicrocrystallites in PVG.

Figure 7 shows the PL decay curves of the CdS/ PVG (e) shown in Fig. 6 obtained by $\mathrm{N}_{2}$ laser excitation at room temperature. In the figure, curve (a) shows the decay curve of PL emission at $405 \mathrm{~nm}$ and curve (b) at $615 \mathrm{~nm}$. The decay time was estimated to be $450 \mathrm{~ns}$ at $615 \mathrm{~nm}$ by assuming an exponential function. In this experiment, the decay time at 405 $\mathrm{nm}$ was under the instrumental response $(1 \mathrm{~ns})$. 


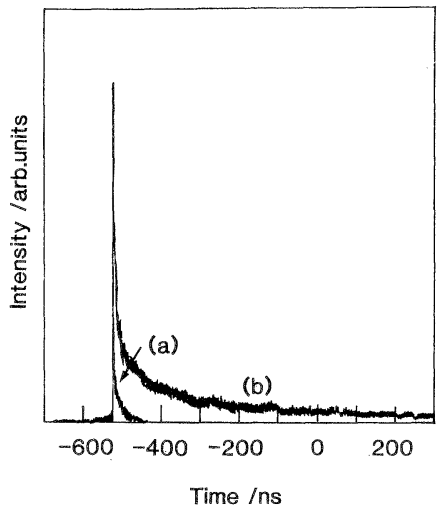

Fig. 7. Decay curves of PL emission (a) monitored at $405 \mathrm{~nm}$ and (b) at $615 \mathrm{~nm}$ for the CdS/PVG (e) shown in Fig. 6.

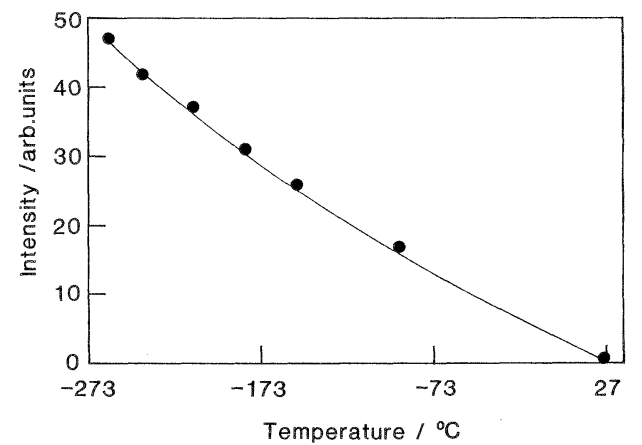

Fig. 8. Temperature dependence of the PL emission intensity at $615 \mathrm{~nm}$ for the CdS/PVG (e) shown in Fig. 6.

Thus the decay time at $615 \mathrm{~nm}$ was at least three orders of magnitude larger than that at $405 \mathrm{~nm}$. The temperature dependence of the emission intensity at $615 \mathrm{~nm}$ for the CdS/PVG (e) is shown in Fig. 8. The intensity increases with decreasing the temperature. The intensity at $-261^{\circ} \mathrm{C}$ was about 65 times larger than that at $27^{\circ} \mathrm{C}$. This is because that the probability of non-radiative transition became lower with decreasing the temperature.

Figure 9 shows the PL emission spectra of CdS/ PVG containing $1.2 \mathrm{wt} \%$ of cadmium. After the reaction with $\mathrm{H}_{2} \mathrm{~S}$ at $150^{\circ} \mathrm{C}$ for $10 \mathrm{~min}$, the $\mathrm{CdS} / \mathrm{PVG}$ was heat-treated at different temperature in air for 30 min. The non-heat-treated CdS/PVG indicated as R.T. in the figure shows the broad emission with a peak at $540 \mathrm{~nm}$. The peak position shifts to longer wavelength $(582 \mathrm{~nm})$ when the CdS/PVG heat-treated at $100^{\circ} \mathrm{C}$. On the other hand, in the spectrum for the CdS/PVG heat-treated at $200^{\circ} \mathrm{C}$, the blue-shifted band-edge emission at $490 \mathrm{~nm}$ can be observed. When the heat treatment temperature increased up to $300^{\circ} \mathrm{C}$, the emission could not be observed and the yellowish color of the CdS/PVG was discharged. The intensity of the emission around $500-600 \mathrm{~nm}$ decreased with increasing the heat treatment temperature. Thus the CdS in the PVG is easily evaporated by heating the CdS/PVG in air.

Figure 10 shows the effect of $\mathrm{MV}^{2+}$ on the $\mathrm{PL}$

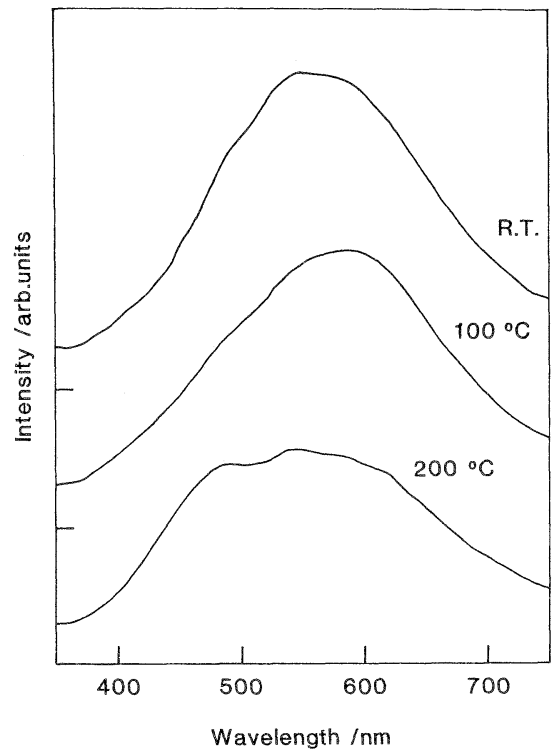

Fig. 9. Heat treatment temperature dependence of the PL emission of CdS/PVG containing $1.0 \mathrm{wt} \%$ of cadmium reacted with $\mathrm{H}_{2} \mathrm{~S}$ at $150^{\circ} \mathrm{C}$.

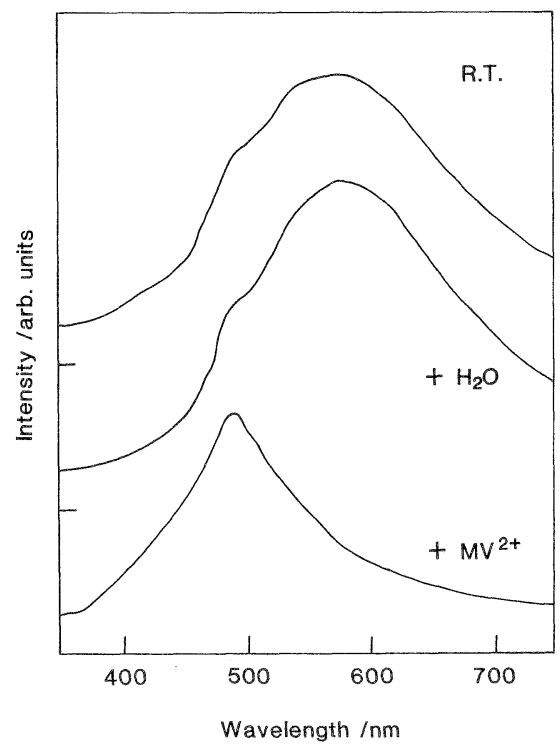

Fig. 10. $\mathrm{PL}$ emission spectra at room temperature for the $\mathrm{CdS} /$ PVG containing $1.2 \mathrm{wt} \%$ of cadmium reacted with $\mathrm{H}_{2} \mathrm{~S}$ at $150^{\circ} \mathrm{C}$ in the absence and presence of water, and of $\mathrm{MV}^{2+}$.

emission of the CdS/PVG containing $1.2 \mathrm{wt} \%$ of cadmium at room temperature. The photogenerated electron-hole pairs of the semiconductor may undergo redox reactions with adsorbed species by reduction of an electron acceptor such as methyl viologen, $\mathrm{MV}^{2+}$. The standard reduction potential of $\mathrm{MV}^{2+}$ is $-0.446 \mathrm{~V}$ vs. NHE, therefore $\mathrm{MV}^{2+}$ could quench the PL emission from surface site by electron transfer from the conduction band electrons of CdSmicrocrystallites to the adsorbed $\mathrm{MV}^{2+}{ }^{22}$ In the figure, it is obvious that water shows no effect on the emission spectrum. On the other hand, the PL emission around $580 \mathrm{~nm}$ is quenched easily within $10 \mathrm{~min}$ 
by addition of $0.005 \mathrm{~mol} \cdot \mathrm{dm}^{-3} \mathrm{MV}^{2+}$. However the blue-shifted band-edge emission at $490 \mathrm{~nm}$ cannot be quenched by $\mathrm{MV}^{2+}$. This again confirmed the emission at $580 \mathrm{~nm}$ was due to a surface state of CdSmicrocrystallites. In this experiment, the quantitative analysis such as the Stern-Volmer plot for $\mathrm{MV}^{2+}$ could not be obtained because of low concentration of CdS deposited in PVG as porous supports.

\section{Conclusions}

(1) In the optical absorption spectra, the CdS/ PVG containing 1.0 at\% of cadmium exhibited a blue shift by about $0.37 \mathrm{eV}$ in comparison with that of the bulk CdS. The blue shift of the CdS/PVG decreased with increasing the diameter of CdSmicrocrystallites in PVG.

(2) The photoluminescence spectra of the CdS/ PVG with 1.2 at\% of cadmium exhibited blue-shifted band-edge emission and the deep level emission. The blue-shifted band-edge emission seems to be a low-dimensional quantum size effect. The deep-level emission was effectively quenched by addition of methyl viologen, suggesting that the emission arose from the surface of CdS-microcrystallites in PVG.

Acknowledgements The authors would like to thank Drs. T. Nitta and K. Kanai for their continuous encouragement.

\section{References}

1) R. K. Jain and R. C. Lind, J. Opt. Soc. Am., 73, 647-53 (1983).

2) N. F. Borrelli, D. W. Hall, H. J. Holland and D. W. Smith, J. Appl. Phys., 61, 5399-409 (1987).
3) H. Jerominek, M. Pigion, S. Patela, Z. Jakubczyk, C. Delisle and R.Tremblay, J. Appl. Phys., 63, 957-59 (1988).

4) J. Yumoto, S. Fukushima and K. Kubodera, Opt. Lett., 12, 832-34 (1987).

5) P. Roussignol, D. Ricard and C. Flyzanis, Appl. Phys. A, 44, 285-92 (1987)

6) J. Warnock and D. D. Awschalom, Phys. Rev. B, 32, 552931 (1985).

7) A. Nakamura, H. Yamada and T. Tokizaki, Phys. Rev. B, 40, 8585-88 (1989).

8) M. Nogami, K. Nagasaka and K. Kotani, J. Non-Cryst. Solids, 126, 87-92 (1990).

9) M. Nogami, K. Nagasaka and K. Kato, J. Am. Ceram. Soc., 73, 2097-99 (1990).

10) N. Touge, M. Asuka and T. Minami, Chem. Express, 5, 52124 (1990)

11) H. Nasu, K. Tsunetomo, Y. Tokumitsu and Y. Osaka, Jpn. J. Appl. Phys., 28, L862-64 (1989).

12) R. Hayashi, M. Yamamoto, K. Tsunetomo, K. Kohno, Y. Osaka and H. Nasu, Jpn. J. Appl. Phys., 29, 756-59 (1990).

13) I. Tanahashi, A. Tsujimura, T. Mitsuyu and A. Nishino, Jpn. J. Appl. Phys., 29, 2111-15 (1990).

14) J. Kuczynski and J. K. Thomas, J. Phys. Chem., 89, 2720-22 (1985).

15) Y. Wang and N. Herron, J. Phys. Chem., 91, 257-60 (1987).

16) R. D. Stramel, T. Nakamura and J. K. Thomas, J. Chem. Soc., Faraday Trans. I, 84, 1287-300 (1988).

17) B. C. Lippens, B. G. Linsen and J. H. de Boer, J. Catalysis, 3, 32-38 (1964).

18) J. A. Taylor, Appl. Surf. Sci., 7, 751-55 (1981).

19) S. W. Gaarenstroom and N. Winograd, J. Chem. Phys., 67, 3500-03 (1977).

20) Y. Kayanuma, Solid State Commun., 59, 405-08 (1986).

21) Y. Wang, A. Suna and J. McHugh, J. Phys. Chem., 92, 6927-39 (1990).

22) J. Kuczynski and J. K. Thomas, J. Phys. Chem., 87, 5498503 (1983). 